\title{
RAÇA NEGRA E EDUCAÇÃO 30 ANOS DEPOIS: MEMÓRIAS E LEGADOS
}

\author{
Petronilha Beatriz Gonçalves e Silva ${ }^{1}$
}

\begin{abstract}
Resumo: Este artigo propõe uma releitura dos artigos publicados nos Cadernos de Pesquisa $n^{\circ}$ 63, que registrou sob a forma de artigos, apresentações e discussões que constituíram o Seminário "O Negro e a Educação" realizado em dezembro de 1986, pela Fundação Carlos Chagas e pelo Conselho de Participação e Desenvolvimento da Comunidade Negra do Estado de São Paulo, com o apoio da Fundação Ford. Naquela oportunidade, pesquisadores de questões relativas à educação dos negros brasileiros, ao lado de militantes do Movimento Negro reuniram-se para apresentar, discutir resultados de pesquisas, relatos de experiências. Trinta anos passados, diante de avanços necessários apontados por pesquisas, propostos pelo Movimento Negro, e vêm-se garantida pelas Leis 10639/2003 e n. 12645/2008 a obrigatoriedade do ensino de história e cultura dos Afrodescendentes, dos Africanos, também dos Povos Indígenas, bem como a Lei Lei ${ }^{\circ} 12.990$ de 09 de junho de 2014 que estabelece políticas de ações afirmativas para negros, Povos indígenas, empobrecidos nas universidades públicas, mantidas pelo poder público federal. Conclui-se, o artigo, sublinhando a importância de que pesquisas continuem sendo realizadas com o comprometimento de buscar o intercâmbio entre o mundo acadêmico e as experiências de mulheres, homens, crianças negras, contribuindo para a construção de um projeto de sociedade em que cada pessoas seja respeitada e valorizada nas suas especificidades.
\end{abstract}

Palavras-chave: Negro e Educação; Pesquisa; Cadernos de Pesquisa 6330 anos.

\section{BLACK RACE AND EDUCATION 30 YEARS LATER: MEMORIES AND LEGACIES}

\begin{abstract}
This article proposes a re-reading of the articles published in Cadernos de Pesquisa (Research Notebooks) no. 63, which recorded in the form of articles, the presentations and discussions that constituted the Seminar "The Negro and the Education". The Carlos Chagas Foundation and The Council for Participation and Development of the Black Community of the State of São Paulo held the event in December 1986, with the support of the Ford Foundation. On that occasion, researchers on issues related to the education of black Brazilians, along with Black Movement militants gathered to present and discuss research results as well as experiences reports. Thirty years passed, in the face of necessary advances pointed out by researches, proposed by the Black Movement, have been guaranteed by Laws 10639/2003 and n. 12645/2008 the obligation to teach the history and culture of Afrodescendants, Africans and Indigenous Peoples. Likewise, Law No. 12,990 of June 9, 2014 establishes affirmative action policies for blacks, Indigenous Peoples and impoverished in public universities, maintained by the federal public power. The article concludes by stressing the importance of continuing research with the commitment to seek the exchange between the academic world and the experiences of women, men and black children, contributing to the construction of a society project in which each person is respected and valued in their specificities.
\end{abstract}

Key-words: Black and Education; Search; Cadernos de Pesquisa no. 6330 years.

\section{RACE NOIRE ET ÉIDUCATION 30 DEPUIS: MÉMOIRES ET LEGS}

\footnotetext{
${ }^{1}$ Professora Emérita da Universidade Federal de São Carlos.E-mail: dpbs@ ufscar.br, pbgs@ @erra.com.br 
Résumé: Cet article propose une relecture des articles publiés dans le Cahiers de Recherche ${ }^{\circ}$ 63 (Cadernos de Pesquisa), qui a enregistré sous la forme d'articles, des présentations et des discussions qui ont été le Séminaire "O Negro e a Educação", réalisé en Décembre 1986 par Fundação Carlos Chagas et par le Conseil de Participation et de Développement de la Communauté Noire de l'État de São Paulo (Conselho de Participação e Desenvolvimento da Comunidade Negra do Estado de São Paulo), avec le soutien de la Fondation Ford. À cette opportunité, des chercheurs sur des questions liées à l'éducation des Brésiliens noirs, joint des militants du Mouvement Noir se sont réunis pour présenter, discuter des résultats de recherche et des rapports d'expériences. Trente ans ont passé, face aux progrès nécessaires signalés par les recherches, proposées par le Mouvement Noir, et garantis par les lois 10639/2003 et n. 12645/2008 l'obligation d'enseigner l'histoire et la culture des afro-descendants, des Africains et des Peuples Autochtones, bien comme la loi $\mathrm{n}^{\circ} 12.990$ du 9 juin 2014, qui établit des politiques d'action positive pour les Noirs, les Peuples autochtones, appauvris dans les universités publique, maintenu par le gouvernement fédéral. L'article a conclu, en signalant l'importance de continuer rechercher avec l'engagement de chercher des échanges entre le monde académique et les expériences des femmes, des hommes, des enfants noirs, aidant à construire d'un projet de société dans lequel chaque personne soit respectée et valorisée dans ses spécificités.

Mots-clés: Noir et Éducation; Recherche; Cahiers de Recherche 6330 ans.

\section{LA RAZA NEGRA Y LA EDUCACIÓN 30 AÑOS DESPUÉS: MEMORIAS Y LEGADOS}

Resumen: Este artículo propone una relectura de los artículos publicados en los Cadernos de Pesquisa $\mathrm{n}^{\circ}$ 63, que registró bajo la forma de artículos, presentaciones y discusiones que constituyeron el Seminario "El Negro y la Educación" realizado en Diciembre de 1986, por la Fundação Carlos Chagas (Fundación Carlos Chagas) y por el Conselho de Participação e Desenvolvimento da Comunidade Negra do Estado de São Paulo (Consejo de Participación y Desarrollo de la Comunidad Negra del Estado de São Paulo), con el apoyo de la Fundación Ford. En esa oportunidad, investigadores de cuestiones relativas a la educación de los negros brasileños, al lado de militantes del Movimiento Negro se reunieron para presentar, discutir resultados de investigaciones, reportes de experiencias. Treinta años pasados, frente a avances necesarios apuntados por investigaciones, propuestos por el Movimiento Negro, y se ven garantizadas por las Leyes 10639/2003 y n ${ }^{\circ} 12645 / 2008$ la obligatoriedad de la enseñanza de historia y cultura de los Afrodescendientes, de los Africanos, también de los Pueblos Indígenas, así como la Ley n 12.990 de 9 de junio de 2014 que establece políticas de acciones afirmativas para negros, pueblos indígenas, empobrecidos en las universidades públicas, mantenidas por el poder público federal. Se concluye, el artículo, subrayando la importancia de que las investigaciones continúen siendo realizadas con el compromiso de buscar el intercambio entre el mundo académico y las experiencias de mujeres, hombres, niños negros, contribuyendo a la construcción de un proyecto de sociedad en que cada persona sea respetada y valorada en sus especificidades.

Palabras-clave: Negro y Educación; La Investigación; Cadernos de Pesquisa 6330 años.

Quando se denuncia a discriminação - o que é raro -, há um medo de as pessoas discriminadas passarem a ser taxadas de discriminadoras. Mas, quando se demonstra isso com dados, as pessoas conseguem perceber. (Romão, 1987, p. 139) 
A publicação do número 63 dos Cadernos de Pesquisa, da Fundação Carlos Chagas (FCC) reúne artigos e registros de debates provocados pelo seminário O Negro e a Educação, em dezembro de 1986, na sede da Fundação, em São Paulo. Trinta anos depois, reuniram-se muitos dos que participaram daquele encontro, bem como outras pessoas interessadas em conhecer mais, discutir significados que ficaram registrados nessa publicação, bem como traçar encaminhamentos ainda necessários para resolver a séria problemática de persistente racismo na educação brasileira.

O seminário de 1986 foi organizado por solicitação do Conselho de Participação da Comunidade Negra e com sua colaboração. Na oportunidade, reuniram-se pesquisadores com experiências consolidadas, pesquisadores iniciantes, militâncias do Movimento Negro - a maioria dos participantes eram negros, a maioria dos pesquisadores experientes, não.

O seminário, do ponto de vista dos militantes do Movimento Negro, foi valioso. De um lado, por verem expostas, em resultados de pesquisas, muitas das denúncias que, há muito, faziam. De outro, por terem conhecido, entrado em contato, convivido, conversado, discutido com negras e negros de diferentes estados do país. Esse intercâmbio consolidou e, em muitos casos, gerou amizades firmes, além, é claro, de parcerias.

No Posfácio da publicação em pauta, Percy da Silva² assim se manifesta:

O objetivo do erro é o objetivo último deste Caderno.

Existe a leitura e a outra leitura proposta neste caderno.

Diante da ditadura dos acertos, democraticamente, erramos. Erramos, inclusive, contra a democracia, aquela dita racial, que denunciamos como falácia. (1987, p. 151)

E conclui Percy:

Por entre esta densa nuvem de "verdades", insistimos em trilhar pelo caminho dos erros em busca de uma identidade, em busca de um conceito de negro, muito mais consistente que o pardo, o sem cor. Aqui a desobediência tem cor e ela é negra. (1987, p. 151)

\footnotetext{
${ }^{2}$ Integrante do Grupo de Trabalho para Assuntos Afro-Brasileiros da Secretaria de Estado de Educação de São Paulo.
} 
A conclusão de Percy sublinha o clima denso e tenso do encontro que exibiu o que se estava de melhor produzindo, tanto em termos científicos como de militância negra, sobre questões relativas à raça negra na educação, no Brasil (1987).

O Conselho de Participação da Comunidade Negra de São Paulo e a FCC, com o referido seminário, demonstraram a importância da pesquisa sobre negros e educação, ao garantir o confronto de formulações feitas por pesquisadores experientes, não negros, com as de pesquisadores negros iniciantes, também com militantes junto ao Movimento Negro.

Sociedade e academia se juntaram e se confrontaram. Confronto não no sentido de briga, embora desentendimentos surgissem, mas no de expor, com firmeza, concordâncias e divergências. Estavam de igual para igual - os que pesquisavam e os que eram usualmente pesquisados, sem ter seus pontos de vista privilegiados.

Perspectivas se cruzaram e diálogos, mais ou menos tensos, se estabeleceram. Os negros e negras, usualmente objetos ou sujeitos de pesquisa, chegavam com conhecimentos ideológicos e teóricos fundamentados tanto na vida como na literatura. Apontavam referências teórico-metodológicas que cabiam, ou não, para estudar a questão racial. Melhor dizendo, expunham a complexidade das relações étnico-raciais, na perspectiva dos negros, e a pertinência ou não de encaminhamentos teóricometodológicos para pesquisas sobre racismo na educação brasileira, notadamente nos currículos, em materiais didáticos, em relações pedagógicas. A publicação em pauta, sutilmente, registrou divergências e, com prudência, destacou convergências.

Cadernos de Pesquisa n. 63, que foi celebrado, lá em 1987, tanto por estudiosos da questão racial como pelo Movimento Negro, continua a trazer, ainda hoje, referências para aqueles que se debruçam sobre a problemática racial negra, na educação brasileira.

Os artigos de autoria de militantes do Movimento Negro, em sua maioria relatos de experiências, mostram iniciativas que visavam a proporcionar a pessoas negras, especialmente crianças, adolescentes, jovens, conhecimentos sobre a história, cultura de povos negros e, assim, prepará-los para enfrentar o racismo, afirmarem-se enquanto cidadãos descendentes de africanos. Tanto esses artigos como os relatos de pesquisa tencionavam elucidar efeitos do racismo na educação de crianças e de jovens negros, 
notadamente nos estabelecimentos de ensino. Tanto aqueles como esses puderam, e ainda podem, fornecer elementos para formulação de políticas públicas de combate ao racismo e fortalecimento da identidade de pessoas negras, afrodescendentes.

Assim, dados de pesquisas, bem como resultados de atividades promovidas por entidades do Movimento Negro, informam, com precisão, sobre a séria problemática do racismo a ser enfrentada, pela sociedade, principalmente pelos sistemas de ensino, ainda nos dias de hoje.

Negros e educação não é simplesmente uma temática, mostra Cadernos de Pesquisa n. 63. Trata-se de questões complexas que desafiam toda a sociedade brasileira a buscar meios para superar efeitos da crueldade de preconceitos racistas. A publicação do periódico em pauta se constitui em importante iniciativa de combate ao racismo na pesquisa em educação, ao registrar dados, informações, contradições, encaminhamentos que denunciam efeitos nefastos do mito da democracia racial, notadamente na educação. Mais do que isso, os artigos chamam a atenção para pesquisas e outras iniciativas necessárias para sustentar políticas públicas que visem a iguais oportunidades sociais, principalmente educacionais, para os negros ${ }^{3}$.

Esse é o caso da apresentação feita pela professora Idelzuita, do Quilombo Mimbó, no Piauí, que chamou a atenção dos que desconheciam, a maioria, a realidade vivida em um quilombo, bem como desafios de educação escolar ali oferecida. Sua exposição causou surpresa e, ainda hoje, seu artigo desperta indignação e sobretudo aponta desafios para a sociedade brasileira:

Essa é a experiência da nossa escola, a experiência do nosso povo. A nossa é esquecida, porque nosso povo é esquecido. [. . .] Nós somos tratados como se não fôssemos gente como os outros. Tudo para nós é mais difícil. A única coisa mesmo nossa é o nosso povo e nossa terra. E a nossa terra estão até tomando de nós. (Paixão, 1987, p. 114)

Ainda sobre comunidade rural $^{4}$, cuja população é majoritariamente negra e constituída por pessoas com laços de parentesco, foi apresentada pesquisa a respeito de formação da identidade e socialização de negros trabalhadores rurais, em que se afirma

\footnotetext{
${ }^{3}$ Ver, por exemplo: Araujo (1987), Chaia (1987), Rosemberg (1987), Hasenbalg (1987), Luiz Alberto Gonçalves (1987).

${ }^{4}$ Trata-se de localidade do município de Palmares do Sul/RS. Em 2004, o Limoeiro foi reconhecido como Comunidade Quilombola.
} 
como motivo do constituir-se pessoa, cidadã negra/o, o enegrecer a sociedade, o mundo:

Enegrecer o mundo, eis nosso motivo. Enegrecer não como antônimo de embranquecer, portanto, não para absorver o branco [...] enegrecer, face a face em que o negro e o branco se espelham, se comunicam, sem deixar de ser cada um o que é. (Silva, P., 1987, p. 147)

Para enegrecer o seminário em que se encontraram pesquisadores e militantes do Movimento Negro, esses contribuíram, discorrendo sobre e avaliando atividades que desenvolviam junto a escolas públicas, bem como ações comunitárias entre população negra. Assim, ao mesmo tempo, denunciavam racismo na educação, bem como buscavam convencer pesquisadores a participar de sua superação, dispondo-se mais a compreender os pontos de vista dos negros do que em ditar-lhes lições.

Entidades de distintas regiões do país tiveram apresentadas, por integrantes de seus quadros, experiências, avaliações e propostas de combate ao racismo, por meio da educação. Ouviram-se e registraram-se depoimentos indignados, propostas fundadas, de um lado, em experiências de sofrer consequências do racismo, bem como de combatêlo; e, de outro, na esperança de que pesquisas pudessem se tornar aliadas no combate ao racismo. É o que expressou a representante do Centro de Cultura Negra do Maranhão:

Hoje, lutamos para a modificação das relações interpessoais, combatendo as formas de racismo, buscamos uma sociedade democrática e mais humana... (Leite, 1987, p. 112)

Apontaram-se dificuldades para integrar, em escolas, atividades relacionadas à cultura negra, bem como estratégias criadas por diretora, professores, notadamente negros, a fim de introduzir atividades e projetos, com vistas a combater discriminação racial (Santos, Adélia, 1987). Também foram apontadas dificuldades de o Movimento Negro ter acolhida, em escolas, sistemas de ensino, propostas para valorização da cultura negra, como meio de combater o racismo. Nesse sentido, veja-se, por exemplo posicionamento da direção de um sistema de ensino:

[...] o coordenador municipal de ensino via, em nosso trabalho, uma competição ou desestabilização de suas ideias, já que a nova proposta levava professores, pais, alunos a discutirem a escola, seus objetivos, sua função e a própria coordenadoria de ensino. (Araujo, Z., 1987, p. 115)

Ao relatar experiências, tanto de entidades, como de iniciativa individual, militantes do Movimento Negro expuseram tensões, dificuldades, também êxitos 
obtidos, para proporcionar a crianças, adolescentes, jovens negros, conhecimentos relativos à história, cultura de seus antepassados e de povos africanos na atualidade. Entendia-se ser essa a maneira de prepará-los para enfrentar o racismo e afirmarem-se enquanto cidadãos brasileiros, descendentes de africanos, entre outros: Deus (1987), Leite (1987), Zezito Araujo (1987), Kátia Silva (1987), Raimundo Gonçalves (1987) e Romão (1987).

Experiências com vistas a divulgar as raízes culturais brasileiras de origem africana e, assim, fortalecer a identidade das pessoas negras, foram descritas, comentadas, apontando-se dificuldades, contradições. Saliente-se, mais uma vez, que essas experiências visavam também a atingir escolas e seus professores (Mello, 1987; Souza, 1987). Entre elas foram apresentadas iniciativas que tinham o objetivo de apoiar e mesmo garantir a implantação de uma das primeiras políticas públicas curriculares formuladas no país, no sentido de combater o racismo, por meio do ensino da história e cultura dos afrodescendentes. Trata-se de iniciativa da Secretaria de Educação do Estado de São Paulo, que, por meio da Resolução n. 95/1986 e em colaboração com o Conselho de Participação e Desenvolvimento da Comunidade Negra, estabeleceu o projeto Salve 13 de Maio? (Silva, Aloízio, 1987; Dias, 1987). Insistiam os responsáveis pela sua implantação que o título do projeto era uma pergunta e não uma afirmação.

Não somente a Educação Básica esteve focalizada nas exposições e debates, durante o seminário. Entidades do Movimento Negro mostraram sua atuação, enfatizaram suas lutas, com o objetivo de um lado de buscar aliados em universidades e de outro de ali introduzir estudos de interesse da população negra. Assim, sugeriram, propuseram que se incluísse, na Educação Superior, disciplinas e temas de pesquisa relativos a histórias e culturas afrodescendentes. Entendia-se ser essa importante medida para combater o racismo na sociedade, notadamente em estabelecimentos de ensino. Notáveis esforços mostraram essas entidades, para articular sociedade, educação, vida e produção universitárias, na perspectiva dos afrodescendentes (Silva, C., 1987; Santos, G., 1987.

Também foi objeto de apresentação e debates, experiência formulada e desenvolvida no quadro da Irmandade de Nossa Senhora do Rosário dos Homens Pretos, na cidade de São Paulo, com a finalidade de oferecer, para adultos (Rodrigues, 
1987), condições para alfabetização e estudos. Note-se que as irmandades religiosas, nos tempos do regime escravista, corresponderam ao que hoje se designa como entidade do movimento social negro. Nessas entidades, bem como em outras organizadas e mantidas por escravizados foram gestados princípios, objetivos, metas, estratégias que, hoje, cabe a entidades do Movimento Negro conduzir.

Centrais nas apresentações foram questões relativas à construção e fortalecimento da identidade dos negros. Esta era e continua sendo forte preocupação do Movimento Negro que entende que, para melhor combater o racismo, é preciso fortalecer o pertencimento a raízes africanas. Helena Theodoro Lopes destacou identidade como: "construção que cada um faz de si mesmo como pessoa" e "É buscar nos valores negros uma nova ideia de pessoa" (1987, p. 38-39). Cabe lembrar que estávamos em um período em que após ter, o Movimento Negro, sublinhado o significado positivo da designação negro: negro é consciência, preto é cor; passou também a enfatizar seu vínculo a culturas africanas, designando-se também como afrodescendentes.

Durante o seminário, relataram-se resultados de pesquisas cujo objetivo era o de situar, na escolarização de crianças negras, relações entre processos de socialização e de construção da identidade afrodescendente. Os resultados obtidos denunciavam estereótipos relativos a pessoas negras utilizados como meio para cultivar racismo, discriminações e, assim, garantir relações de dominação-subordinação entre brancos e negros (Pereira, 1987, p. 44):

[...] admitir identidades específicas de grupos étnicos, como o negro, é admitir a existência de problema racial no país, o que contraria a tese ou o mito da democracia racial, valor supremo de nosso modelo de convivência pluriétnica.

Maria de Lourdes Teodoro, na mesma linha de considerações, pondera que os "conteúdos da educação precisam ser meios para realizar sua identificação consigo mesmo e com sua cultura". E conclui a pesquisadora que "o etnocentrismo em um país formado por vários grupos étnicos é negador da identidade nacional” (Teodoro, 1987, p. 47).

Ainda nesse foco de denúncias, raciocínios, ponderações, tanto Cunha Jr. (1987) como Barbosa (1987), embora em perspectivas distintas, tecem considerações sobre 
como os pais ajudam ou não crianças negras a enfrentar discriminação racial no ambiente escolar. As duas pesquisas sublinham inseguranças das famílias negras para orientar seus filhos, bem como despreparo de professores e funcionários das escolas, para combater a discriminação racial. Cunha Jr. destaca que "o desempenho escolar tem forte interação com a qualidade das relações raciais" (1987, p. 53). Enquanto Irene Barbosa (1987, p. 55) sublinha o "desafio de aparelhar a escola, os (as) professores(as), para que de alguma forma [...] possam influir no processo socializador das crianças negras, minimizando as situações traumáticas".

Os registros dos debates permitiram que se observasse resistência diante de resultados de pesquisas, opiniões sobre jeitos de ser, de pensar, de viver dos negros, que, embora formulados com base em literatura científica, revelavam equívoco nas interpretações, em virtude de desconhecimento de reais vivências da população negra, de seus pensamentos, projetos de vida, até mesmo projeto de nação. Reagiam, os negros presentes, pesquisadores, militantes do Movimento Negro, como o fez Maria de Fátima Viana (1987, p. 60):

No que diz respeito às pesquisas sobre identidade, acho importante se tentar partir de referencial teórico mais favorável à comunidade negra. Penso que é falso se afirmar que a cultura negra não tem referencial de identidade. A cultura negra tem um referencial de identidade, pelo menos no Maranhão, uma família negra sabe o que é vencer na vida, tem referencial moral, social, uma postura filosófica diante do mundo.

Assim, os debates, em alguns pontos mais ricos do que dados e conclusões de pesquisas, do que descrição de experiências exibiram, com nitidez, que, para estudar a questão racial negra, referências teóricas, metodologias que desconsiderassem peculiaridades de visões de mundo, jeitos de ser e viver, formas de pensar de organizar a vida dos negros e negras, levavam, muitas vezes, a conclusões equivocadas. Helena Teodoro, uma das primeiras mulheres militantes do Movimento Negro a defender tese de doutorado, entre outras questões, destacou a razão de manifestações de integrantes do Movimento Negro:

O negro tem que trabalhar o problema do negro, por causa das contradições, das distorções, do racismo neste país. Concordo também que precisamos estudar o branco, não sabemos nada sobre ele, mas também não sabemos sobre nós. (1987, p. 58) 
Interprete-se esse final de afirmação, no sentido de que ainda eram escassos os dados de pesquisa que mostravam a realidade das desigualdades entre negros e brancos. Sabíamos de nossas desvantagens, mas era preciso aumentar as investigações com o objetivo de medi-las, exibi-las, criticá-las para que todos soubessem a respeito das profundas desigualdades que constituem a sociedade brasileira.

Assim, com firmeza, entre certezas e equívocos, pesquisadores experientes, iniciantes, ativistas junto ao Movimento Negro teciam afirmações, elaboravam questões, formulavam críticas e encaminhamentos de propostas. Entre elas, cabe citar contundente afirmação de Luiz Alberto Gonçalves, no sentido de que é fundamental:

[...] compreender mecanismos do ritual pedagógico que exclui dos currículos escolares, a história de luta dos negros na sociedade brasileira; que impões às crianças negras um ideal de ego branco; que produz um discurso sobre o tratamento igual às crianças brancas e não brancas. (1987, p. 27)

No mesmo sentido de preocupações, pesquisa realizada pela FCC, a pedido da Secretaria da Educação de São Paulo, por sugestão do Conselho da Comunidade Negra, revelou omissão, nos currículos escolares, a respeito da "pluralidade étnico-racial da sociedade, omissão essa que se reflete [...] num currículo escolar inadequado à criança negra", destaca Rachel de Oliveira (1987, p. 64). E continua essa professora e pesquisadora:

Precisamos analisar o currículo mais cuidadosamente, não só no que se refere à cultura negra, mas no seu aspecto geral, para que esse currículo evite a seletividade e garanta um alto grau de escolaridade, aos alunos das classes populares. (Oliveira, 1987, p. 64)

Nessa perspectiva apontada por Oliveira, apresentaram-se experiências de implantação de políticas públicas, na Bahia (Santos, Arany, 1987), no município do Rio de Janeiro (Ferreira, 1987) e na cidade de Brasília (Cruz, 1987). Como se vê, a Lei n. 10639/2003 não foi uma casualidade. Esse importante instrumento legal vinha sendo construído pelo Movimento Negro, por educadores negros e não negros, que, com ações pedagógicas, foram fundamentando essa política, necessária para aperfeiçoar a democracia brasileira. Nesse sentido, cabe destacar a proposta da Pedagogia Interétnica, formulada por Manoel de Almeida Cruz (1987), que tem, como perspectiva, 
peculiaridades e necessidades de populações negras e indígenas. Com firmeza, o autor expõe fundamentos de sua proposta:

[...] a pedagogia interétnica [...] está preocupada e ocupada com a essência do ente humano, com sua libertação total, não somente através da interpretação da realidade, mas da sua transformação radical. (Cruz, 1987, p. 76)

Como se vê, centrais nas apresentações e discussões do seminário estavam processos de socialização de crianças negras, sobretudo em escolas, atentando-se para a formação da sua identidade, enquanto descendentes de africanos, de pessoas escravizadas que souberam recriar sua humanidade, sem perder suas raízes primeiras. Nesse sentido, no Caderno no. 63, críticas se fazem enfaticamente à omissão dessa história, em livros didáticos e infanto-juvenis. Negrão (1987), entre outras questões, sublinha que, se, de um lado, se faziam não poucas denúncias de omissões e de preconceitos, de outro faltavam e, hoje, ainda faltam iniciativas firmes para corrigir distorções a respeito da contribuição dos negros, para a cultura brasileira, para a edificação da nação. Diante de constatações como essas, Pahim Pinto (1987), entre outras providências, destaca a importância de a formação de professores ficar atenta à análise crítica de materiais didáticos. Já Triumpho (1987, p. 93) sublinha serem “os livros didáticos o principal instrumento de aprendizagem do alunado brasileiro", e que reforçam preconceitos e racismo contra os negros. Destaca ela que inclusive textos utilizados em catequese pela igreja católica apresentam afirmações e imagens de cunho racista.

Na mesma linha de denúncias, Ana Célia da Silva enfatiza que o sistema de ensino da sociedade brasileira privilegia "a cultura branca com o objetivo de promover a desaculturação e o branqueamento" (1987, p. 96). E Rufino dos Santos (1987, p. 99) pergunta se o livro didático seria um mal necessário, além de avaliar que se trata "de mero condutor de ideologia, um mero multiplicador de preconceitos... o que é profundamente perverso".

Ademil Lopes (1987, p. 102), que aborda o livro didático na perspectiva de professor dos anos iniciais de educação básica, pondera:

[...] a problemática do livro sintetiza a problemática da escola pública que é produto da sociedade dominante, portanto é importante que a discussão de uma não se faça sem a outra. 
O n. 63 de Cadernos de Pesquisa se propõe, em distintas perspectivas, a apontar questões, desenvolver temáticas que, em meados de 1980, a pesquisa sobre educação de negros privilegiava. Essas se ocupavam de anos de escolarização, rendimento escolar, na perspectiva de identificação/identidade racial. Pesquisadores experientes, à guisa de diagnóstico, trouxeram dados, conclusões contundentes.

Assim, Tereza Cristina Araújo (1987, p. 15) destaca que "na sociedade brasileira a cor é a metáfora, a categoria mais frequentemente acionada para demarcar diferenças e desigualdades com base na raça". Já Chaia (1987) sublinha que as maiores taxas de desemprego estavam entre pessoas negras, e as de emprego, entre as brancas. Enquanto Rosemberg (1987, p. 22) denuncia que "[...] o sistema escolar interpõe ao alunado negro uma trajetória escolar mais difícil que aquela que interpõe a crianças brancas".

No mesmo sentido desta conclusão, Hasenbalg (1987, p. 26), com precisão, argumenta, citando pesquisa (Dias, 1979) que conclui estarem os professores mal aparelhados para lidarem com as "heterogeneidades de classe, heterogeneidades étnicas ou raciais. Basicamente a ideia é de que a atuação do professorado está permeada pela ideologia que legitima as desigualdades sociais".

Aqui vale um breve parêntese para lembrar que essa ideia vigora hoje, entre alguns professores universitários contrários à política de ações afirmativas. Argumentam eles que os estudantes egressos de escolas públicas, entre eles, negros, embora tendo passado pelo crivo das provas do vestibular, seriam menos capacitados do que os oriundos de escolas privadas, para estudos em nível superior.

Como se vê, resultados de pesquisas, relatos de experiências, registros de debates do Cadernos n. 63 continuam atuais.

Os registros dos ricos debates, estimulados pelos relatos de pesquisas, bem como de experiências, exibiram a importância, para estudar a questão racial negra, de referências teóricas, de metodologias que tenham em conta peculiaridades de situações vividas por pessoas negras, visões de mundo suas, jeitos de ser e viver, formas de pensar, de organizar a vida, de lutar contra desigualdades, projeto de sociedade. Assim, necessário se faz que se busquem referências em pesquisadores, autores africanos, afrodescendentes em distintas diásporas, a fim de investigar, com propriedade, a séria problemática das desigualdades étnico-raciais. 
Como já se viu, Cadernos de Pesquisa n. 63 reúne relatos, preocupações, sugestões, principalmente dados e informações que permitem constatar que, em meados de 1980, a pesquisa sobre educação dos negros brasileiros privilegiava questões relativas a anos de escolarização, rendimento, identidade racial. Problemática essa que continua, ainda em nossos dias, a provocar, desafiar pesquisadores comprometidos com projeto de sociedade em que todos tenham seus direitos respeitados, garantidos.

Como bem sublinhou o representante da Fundação Ford, Peter Fry, que apoiou a realização do seminário, essa foi uma "oportunidade ímpar para reunir pessoas militantes, pesquisadores, professores - que vinham trabalhando isoladamente ou com pouco contato entre si” (1987, p. 4).

Antes de concluir, é importante sublinhar que a publicação que aqui examinamos, tentando juntar registros e lembranças, bem como articular uma interpretação, 30 anos passados, iniciativa da FCC em articulação com o Conselho de Participação da Comunidade Negra, foi, de certa forma, sendo projetada, pelo Movimento Negro brasileiro, ao longo do século XX. Entre muitas iniciativas que antecederam o seminário registrado na publicação em pauta neste artigo, aponto algumas que me vêm à lembrança.

Cara/o leitora/or, esteja certa/o que muitas outras ocorreram, com maior ou menor abrangência, por todo o país. Minhas recordações e registros permitem-me citar:

- os FECONEZU ${ }^{5}$, no estado de São Paulo;

- os encontros dos Negros do Norte e do Nordeste;

- as iniciativas, Brasil afora, do Movimento Negro Unificado (MNU), do União e Consciência Negra, dos Agentes de Pastoral Negros;

- os encontros de entidades como o CEDENPA ${ }^{6}$, no Pará, o NEN ${ }^{7}$, em Santa Catarina; e - o I e II Encontro sobre Educação do Negro no Brasil, em Porto Alegre, coordenados pela Prof ${ }^{a}$ Vera Regina dos Santos Triumpho e organizados pela Sociedade Recreativa e Cultural Floresta Aurora, em 1984 e 1985.

\footnotetext{
${ }^{5}$ Festival Comunitário Negro Zumbi

${ }^{6}$ Centro de Estudos e Defesa do Negro no Pará

${ }^{7}$ Núcleo de Estudos Negros
} 
Ao seminário de 1986 e à publicação que, com competência, registrou muito do apresentado, debatido, proposto, outras oportunidades na mesma linha de objetivos e proposições se seguiram. Cabe lembrar que, em 1987, sob a coordenação do Prof. Luiz Alberto Oliveira Gonçalves, a Fundação João Pinheiro, de Belo Horizonte, promoveu o encontro Educação e Discriminação dos Negros, que proporcionou novos intercâmbios entre muitos dos que estiveram, em São Paulo, em 1986, além de incluir novos participantes, entre eles, técnicos de secretarias de educação. Discussões se aprofundaram, avançaram, levaram a novas direções; veja-se, nesse sentido, a publicação Educação e Discriminação dos Negros (Melo; Coelho, 1988)

Muitas outras oportunidades de encontros para discussões, intercâmbios, sempre com o objetivo de aprofundar conhecimentos sobre racismo na educação e apoiar projetos e propostas para superá-lo, se sucederam, organizados na perspectiva da população negra, por iniciativa do Movimento Negro ou de instituições de ensino, especialmente em 1988, quando dos 100 anos de promulgação da Lei n. 3.353/1888 da Abolição da Escravidão no Brasil. Entre muitos outros, cito o organizado na PUC-RS em parceria com a ULBRA, que reuniu pesquisadores nacionais e integrantes do Movimento Negro, para discutir e formular propostas sobre $O$ negro brasileiro: educação e cultura.

Certamente, as leitoras e leitores terão registro de inúmeros outros, que ignoro ou de que não me lembro. O certo é que muitos foram sendo pautados e realizados pela comunidade negra ou com seu apoio, em todas as regiões do país, em municípios e comunidades.

Muitas outras iniciativas se sucederam ou foram fortalecidas, entre elas, publicações, como a Série Pensamento Negro, organizada pelo Núcleo de Estudos Negros, em Florianópolis, que, desde 1997, vem divulgando análises, propostas, críticas no que diz respeito a questões raciais na educação. Importantes contribuições também têm trazido grupos de pesquisa e de militância para o combate ao racismo, bem como de fortalecimento acadêmico-científico de estudantes negros, visando a ampliações de conhecimentos em diferentes áreas das ciências humanas, da saúde, biológicas, tecnológicas, agrárias, para combater o racismo. Esses grupos recebem, muitos deles, designação como núcleos de estudos afro-brasileiros e se encontram organizados em 
consórcio em que se discutem questões-chave de interesse das populações negras, bem como políticas de educação e pesquisa. Entre esses grupos, citam-se alguns: Centro de Estudos Afro Orientais da Universidade Federal da Bahia (UFBA), o Programa de Educação sobre o Negro na Sociedade Brasileira da Universidade Federal Fluminense; Programa de Ações Afirmativas, entre eles o da Universidade Federal de Minas Gerais (UFMG), o da Universidade Federal do Paraná; Núcleo de Estudos e Pesquisas sobre Formação de professores e Relações Étnico-raciais da Universidade Federal do Pará; Núcleos e de Estudos Afro-Brasileiros, entre eles o da Universidade Federal de São Carlos (UFSCar). Cabe também mencionar publicações, como o livro Pensamentos Negros em Educação (Silva; Barbosa, 1997), que registra contribuições de representantes de diferentes entidades do Movimento Negro que, em 1995, participaram de importante seminário sobre pensamentos negros no $\mathrm{NEAB}^{8} /$ UFSCar.

De um lado, entidades do Movimento Negro, fortalecidas por suas próprias iniciativas, de certa forma também pelos resultados do seminário 63 e pela publicação do número do Cadernos de Pesquisa, buscavam tanto fortalecer famílias e suas crianças para combater o racismo, como sensibilizar escolas; de outro, professores e estudantes negros filiados à Anped (Associação Nacional de Pós-Graduação e Pesquisa em Educação), introduziam nas reuniões anuais da entidade questões relativas a negros e educação.

Assim, em 1992, a Prof ${ }^{a}$ Maria de Lourdes Bandeira, da Universidade Federal de Mato Grosso (UFMT), apresentou o primeiro trabalho sobre educação na perspectiva do Movimento Negro ${ }^{9}$. Nos anos seguintes, o grupo de trabalho (GT)/Anped Movimentos Sociais e Educação passou a acolher discussões sobre multiculturalismo, racismo e discriminações na educação, considerando a perspectiva de negros e de indígenas.

No final dos anos 1990, a Fundação Ford no Brasil propôs à Anped que examinasse a possibilidade de desenvolver programa de formação de pesquisadores negros, interessados em questões relativas a negros na educação. Assim, se constituiu o Concurso Negro e Educação ${ }^{10}$, organizado e implementado pela Anped e Ação

\footnotetext{
${ }^{8}$ Núcleo de Estudos Afro-Brasileiros

${ }^{9}$ Bandeira, M. L. Separatismo, racismo e educação. Interdisciplinaridade Educação, Cuiabá - MT, p. 7691, 1992.

10 A coordenação da orientação científica esteve a cargo das professoras Regina Pahim Pinto, da Fundação Carlos Chagas, e de Petronilha Beatriz Gonçalves e Silva, da UFSCar.
} 
Educativa. Muitos dos que participaram dessa importante possibilidade de formação, hoje são pesquisadores, com produção relevante, em universidades públicas e privadas, em centros de pesquisa. Essa foi uma das primeiras políticas de ação afirmativa na educação, em nosso país.

Dessa forma, na Anped, se fortaleciam, as pesquisas no campo das relações étnico-raciais, o que garantiu que se constituísse o GT 21 - Educação e Relações Raciais.

Claro que não se está atribuindo ao seminário de 1986 e à publicação do número de Cadernos de Pesquisa tudo que seguiu em termos de pesquisa sobre a questão racial na educação, especialmente políticas públicas institucionais ou de Estado. Entretanto, não há como deixar de reconhecer que representam - o seminário e a publicação - um marco, pelo fato de facilitar canais de diálogo, em nível nacional, entre pesquisadores da questão racial e lideranças do Movimento Negro.

Em tempo de concluir, cabe, de um lado, destacar o que tais canais de diálogo possibilitaram, não sem muitas divergências, mas também com fortes convergências, que políticas públicas de Estado e institucionais, ao longo dos anos, fossem sendo formuladas, discutidas, promulgadas, recebendo orientação para serem implantadas. Nesse sentido, cabe citar o importante papel do Conselho Nacional de Educação (CNE), que estabeleceu determinações para que se implantasse o estabelecido pelas leis $n$. $10639 / 2003$ e n. $12645 / 2008^{11}$.

Cabe, por outro lado, mencionar que a FCC tem dado continuidade a compromisso social assumido com a população de brasileiros desprivilegiada em termos econômicos, entre elas, pessoas negras, tendo assumido, com apoio financeiro da Fundação Ford, o desenvolvimento do Programa Internacional de Bolsas. Programa esse que preparou e orientou pessoas com competência acadêmica, pertencentes a grupos sociais de baixa renda, que, sem bolsa de estudos e orientação para pesquisa, não teriam condições de se candidatar e de realizar cursos de mestrado e de doutorado. $\mathrm{Na}$

${ }^{11}$ Nesse sentido, cabe sublinhar resoluções e pareceres do Conselho Nacional de Educação: Parecer CNE/CP n. 3/2004 e Resolução CNE/CP n. 1/2004 que trata das Diretrizes Curriculares Nacionais para Educação das Relações Étnico-Raciais e para o Ensino de história e Cultura Afro-Brasileira e Africana; Resolução CNE/CEB n. 8/2012 e Parecer CNE/CEB n. 16/2012 que define Diretrizes Curriculares Nacionais para a Educação Escolar Quilombola na Educação Básica; Resolução n. 2/2012 e Parecer CNE/CEB n. 13/2012, que define Diretrizes Curriculares Nacionais para a Educação Escolar Indígena na Educação Básica. 
mesma linha de proposta, a FCC promoveu o concurso de dotações para formação préacadêmica - Equidade na Pós-Graduação - e mais recentemente o concurso de pesquisa Negras e Negros nas Ciências.

O presente artigo aqui se encerra, não sem antes instigar os que o lerem a, tendo em conta o contexto político nacional e internacional que tanto nos aflige, perguntar-se e buscar responder, com palavras e ações: Que sociedade precisamos construir? Do que precisamos para fazer frente a novos processos de colonização e os consequentes racismos que nos atingem, afligem, abalam? Se o n. 63 de Cadernos de Pesquisa registra oportunidades de expor, debater, criar e recriar proposições, poderá, ele, ainda, nos dar suporte, ao lado de tantas outras produções de negros e também de não negros, a abrir novas direções?

O Movimento Negro costuma ensinar e Zélia Amador de Deus (2011) não cansa de chamar a atenção ao que os artigos do n. 63 do Cadernos de Pesquisa, de uma forma ou de outra, bem o mostraram - o corpo negro é um discurso político. Assim sendo, cabe concluir este artigo perguntando-se: Como pesquisas podem ajudar a construir pontes entre esses corpos carregados de atrevimento, de história, de conhecimentos enraizados na África, e o mundo acadêmico, altamente conservador, ainda em parte colonizado por mentalidade eurocentrada? Como poderão as certezas das ciências terem em vista experiências de mulheres e homens negros? Como poderão estudos sobre negros e educação contribuir para um projeto de sociedade em que todos os brasileiros estejam incluídos, porque respeitados e valorizados na sua diversidade?

\section{REFERÊNCIAS}

AMADOR DE DEUS, Zélia. O corpo negro como marca identitária na diáspora africana. XI Congresso Luso Afro Brasileiro de Ciências Sociais: Diversidades e (Des)Igualdades. Salvador: Universidade Federal da Bahia, 2011.

ARAUJO, Teresa Cristina N. A classificação de "cor" nas pesquisas do IBGE; notas para uma discussão. Cadernos de Pesquisa, São Paulo, n. 63, p. 14-16, nov. 1987.

ARAUjO, Zezito de Projeto Palmares. Cadernos de Pesquisa, São Paulo, n. 63, p. 115-116, nov. 1987.

BARBOSA, Irene Maria Ferreira. Socialização e identidade racial. Cadernos de Pesquisa, São Paulo, n. 63, p. 54-55, nov. 1987.

CHAIA, Miguel W. Negro, mercado de trabalho e educação na Grande São Paulo. Cadernos de Pesquisa, São Paulo, n. 63, p. 17-18, nov. 1987 
CRUZ, Manoel de Almeida. Pedagogia Interétnica. Cadernos de Pesquisa, São Paulo, n. 63, p. 74-76, nov. 1987.

CUNHA Jr., Henrique. A indecisão dos pais face à percepção da discriminação racial na escola pela criança. Cadernos de Pesquisa, São Paulo, n. 63, p. 51-53, nov. 1987.

DEBATE - processo de socialização da criança e formação da identidade. Cadernos de Pesquisa, São Paulo, n. 63, p. 58, nov. 1987.

DEUS, Zélia Amador de. Centro de Estudos e Defesa do Negro do Pará. Cadernos de Pesquisa, São Paulo, n. 63, p. 108-109, nov. 1987.

DIAS, Maria Teresa. Desigualdades sociais e oportunidade educacional. 1979. Dissertação (Mestrado em Ciência Política e Sociologia) - IUPERJ, Rio de Janeiro, 1979.

DIAS, Ricardo. Osasco: debate e denúncia sobre o racismo. Cadernos de Pesquisa, São Paulo, n. 63, p. 130-131, nov. 1987.

FERREIRA, Vanda Maria de S. Projeto zumbi dos Palmares. Cadernos de Pesquisa, São Paulo, n. 63, p. 72-73, nov. 1987.

GONÇALVES, Luiz Alberto O. Reflexão sobre a particularidade cultural na educação das crianças negras. Cadernos de Pesquisa, São Paulo, p. 27-35, nov. 1987.

GONÇALVES, Raimundo (Bujão). Oficina Infantil de Dança Afro. Cadernos de Pesquisa, São Paulo, n. 63, p. 119-120, nov. 1987.

HASENBALG, Carlos A. Desigualdades sociais e oportunidade educacional: a produção do fracasso. Cadernos de Pesquisa, n. 63, São Paulo, p. 24-26, nov. 1987.

LEITE, Silvia Cristina C. Centro de Cultura Negra do Maranhão. Cadernos de Pesquisa, n. 63, São Paulo, p. 110-112, nov. 1987.

LOPES, Ademil. Livro Didático: uma tentativa de inversão do sinal. Cadernos de Pesquisa, n. 63, São Paulo, p. 101-102, nov. 1987.

LOPES, Helena Theodor. Educação e Identidade. Cadernos de Pesquisa, n. 63, São Paulo, p. 38-41, nov. 1987.

MELLO, Lydia Garcia de. Experiências de Recuperação da Identidade Negra. Cadernos de Pesquisa, n. 63, São Paulo, p. 121-122, nov. 1987.

MELO, Regina Lúcia Couto de; COELHO, Rita de Cássia Freitas (Org.) Educação e discriminação dos negros. Belo Horizonte: Instituto de Recursos Humanos João Pinheiro, 1988.

NEGRÃO, Esmeralda V. A discriminação racial em livros didáticos e infanto-juvenis. Cadernos de Pesquisa, n. 63, São Paulo, p. 86, nov. 1987.

OLIVEIRA, Rachel de. Reflexões sobre a experiência de alteração curricular em São Paulo. Cadernos de Pesquisa, São Paulo, n. 63, p. 64-66, nov. 1987. 
PAIXÃO, Idelzuita Rabelo da. Mimbó: a educação no quilombo. Cadernos de Pesquisa, São Paulo, n. 63, p. 113-114, nov. 1987.

PEREIRA, João Baptista B. A Criança Negra: Identidade Étnica e Socialização. Cadernos de Pesquisa, n. 63, São Paulo, p. 41-45, nov. 1987.

PINTO, Regina Pahim. A representação do negro em livros didáticos de leitura. Cadernos de Pesquisa, n. 63, São Paulo, p. 88-92, nov. 1987.

RODRIGUES, Argeniro. Irmandade Nossa Senhora do Rosário dos Homens Pretos. Cadernos de Pesquisa, n. 63, São Paulo, p. 137-138, nov. 1987.ZEBRA

ROMÃO, Jeruse Maria. Experiências educacionais em Santa Catarina. Cadernos de Pesquisa, São Paulo, n. 63, p. 139-140, nov. 1987.

ROSEMBERG, Fúlvia. Relações raciais e rendimento escolar. Cadernos de Pesquisa, São Paulo, n. 63, p. 10-23, nov. 1987.

SANTOS, Adélia. Escola Municipal Barão de Macaúbas. Cadernos de Pesquisa, n. 63, São Paulo, p. 126-127, nov. 1987.

SANTOS, Arany Santana Neves. Inclusão da Disciplina "Introdução aos Estudos Africanos" no currículo Oficial da Rede Estadual de $1^{\circ}$ e $2^{\circ}$ Graus da Baia. Cadernos de Pesquisa, São Paulo, n. 63, p. 69-71, nov. 1987.

SANTOS, Gevanilda Gomes dos. Grupo Negro da PUC/SP. Cadernos de Pesquisa, São Paulo, n. 63 , p. $135-136$, nov. 1987.

SANTOS, Joel Rufino dos. Livro didático: um mal necessário? Cadernos de Pesquisa, São Paulo, n. 63, p. 99-100, nov. 1987.

SILVA, Aloízio R. da. Minha Visão sobre o Negro na Educação. Cadernos de Pesquisa, São Paulo, n. 63, p. 128-129, nov. 1987.

SILVA, Ana Célia da. Estereótipos e Preconceitos em Relação ao Negro no Livro de Comunicação e Expressão do $1^{\circ}$ Grau. Cadernos de Pesquisa, São Paulo, n. 63, p. 96-98, nov. 1987.

SILVA, Casemiro Paschoal da. Centro de Cultura Afro-Brasileiro Congada de São Carlos. Cadernos de Pesquisa, São Paulo, n. 63, p. 132-134, nov. 1987.

SILVA, Kátia de M. e. Grupo Cultural Olodum. Cadernos de Pesquisa, São Paulo, n. 63, p. 117-118, nov. 1987.

SILVA, Percy da. Posfácio. Cadernos de Pesquisa, São Paulo, n. 63, p. 151, nov. 1987.

SILVA, Petronilha B. G. e. Formação da identidade e socialização no Limoeiro. Cadernos de Pesquisa, São Paulo, n. 63, p. 141-147, nov. 1987.

SILVA, Petronilha B. G. e; BARBOSA, Lúcia M. de A. (Org.). Pensamentos negros em educação: expressões do Movimento Negro. São Carlos: EDUFSCar, 1997. 
SOUZA, Maria José de. Chico Rei Clube de Poços de Caldas. Cadernos de Pesquisa, São Paulo, n. 63, p. 123-125, nov. 1987.

TEODORO, Maria de Lourdes. Identidade, Cultura e Educação. Cadernos de Pesquisa, São Paulo, n. 63, p. 46-50, nov. 1987.

TRIUMPHO, Vera Regina S. O Negro no Livro Didático e a Práticas dos Agentes de Pastoral Negros. Cadernos de Pesquisa, São Paulo, n. 63, p. 93-95, nov. 1987.

VIANA, Maria de Fátima. Debate. Cadernos de Pesquisa, São Paulo, n. 63, p. 60, nov. 1987 ZEBRA 